\title{
Antiviral Activity of Fermented Ginseng Extracts against a Broad Range of Influenza Viruses
}

\author{
Ye Wang ${ }^{1,2,+}$, Yu-Jin Jung ${ }^{1,2,+}$, Ki-Hye Kim ${ }^{1}$, Youngman Kwon ${ }^{1}$, Yu-Jin Kim ${ }^{1,2}$, Zhan Zhang ${ }^{1,2}$, \\ Heun-Soo Kang ${ }^{3}$, Bao-Zhong Wang ${ }^{1}$ id , Fu-Shi Quan ${ }^{1,4}$ and Sang-Moo Kang ${ }^{1,2, *}$ \\ 1 Center for Inflammation, Immunity and Infection, Institute for Biomedical Sciences Georgia State University, \\ Atlanta, GA 30303, USA; ywang91@student.gsu.edu (Y.W.); yjung8@student.gsu.edu (Y.-J.J.); \\ kihyekim4282@gmail.com (K.-H.K.); ymankwon@gmail.com (Y.K.); yujinsm@gmail.com (Y.-J.K.); \\ zzhang12@student.gsu.edu (Z.Z.); bwang23@gsu.edu (B.-Z.W.); fquan01@gmail.com (F.-S.Q.) \\ 2 Department of Biology, Georgia State University, Atlanta, GA 30303, USA \\ 3 Metabolab, Cancer Research Institute, Seoul National University College of Medicine, Seoul 110-799, Korea; \\ metabolab@gmail.com \\ 4 Department of Medical Zoology, Kyung Hee University School of Medicine, Seoul 130-705, Korea \\ * Correspondence: skang24@gsu.edu; Tel.: +1-404-413-3588. \\ + These authors contributed equally to this work.
}

Received: 2 July 2018; Accepted: 27 August 2018; Published: 1 September 2018

\begin{abstract}
Ginseng products used as herb nutritional supplements are orally consumed and fermented to ginsenoside compounds by the intestinal microbes. In this study, we investigated antiviral protective effects of fermented ginseng extracts against different strains of influenza viruses in genetically diverse mouse models. Intranasal coinoculation of mice with fermented ginseng extract and influenza virus improved survival rates and conferred protection against H1N1, H3N2, H5N1, and H7N9 strains, with the efficacy dependent on the dose of ginseng samples. Antiviral protection by fermented ginseng extract was observed in different genetic backgrounds of mice and in the deficient conditions of key adaptive immune components (CD4, CD8, B cell, MHCII). The mice that survived primary virus inoculation with fermented ginseng extract developed immunity against the secondary infection with homologous and heterosubtypic viruses. In vitro cell culture experiments showed moderate virus neutralizing activity by fermented ginseng extract, probably by inhibiting hemagglutination and neuraminidase activity. This study suggests that fermented ginseng extracts might provide a means to treat influenza disease regardless of virus strains.
\end{abstract}

Keywords: fermented ginseng; influenza virus; antiviral activity; hemagglutinin; neuraminidase

\section{Introduction}

Influenza virus is a contagious pathogen that has been causing massive mortality for decades. Among the three major types (type A, B, and C) of influenza virus, type A is more prevalent due to diverse hosts. The Center for Disease Control and Prevention (CDC) estimates that influenza has resulted in between 12,000 and 56,000 deaths annually in the United States since 2010 [1,2]. Two important glycoproteins-hemagglutinin (HA) and neuraminidase (NA) — determine a specific subtype and mediate infection. With a combination of HA (subtype 1 to 18) and NA (subtype 1 to 11), various subtypes of influenza virus can infect different species, including humans, mammals, and birds [3-5]. Among these subtypes of influenza virus, H1N1 and H3N2 are the main strains circulating in humans every season, whereas sporadic transmission and infection with novel H5N1, H7N9, and H5N6 subtypes in humans have been reported recently [6-8]. Vaccination is the main measure used to prevent large-scale infection. However, influenza viruses continue to mutate their genomes, resulting in frequent and high resistance to drugs and vaccines $[9,10]$. 
Panax ginseng has long been reported as one of the most common herbal medicines used in humans. Treatment of mice with ginseng extracts has been reported to reduce the production of inflammatory IL-6 and IL-8 cytokines and to increase antiviral cytokine interferon (IFN)- $\gamma$ upon influenza virus infection [11,12]. Ginseng products are mostly consumed by oral intake. During the digestion process, ginseng ginsenoside compounds ( $\mathrm{Rg} 1, \mathrm{Rb} 1, \mathrm{Rb} 2, \mathrm{Rg} 3)$ are converted into pharmaceutically active components (PPD, Rh2, Compound K, PPT) by bacterial microbes present in human intestines [13]. Fermented ginseng products have been shown to exhibit various biological activities, including antioxidative and antibacterial activities [14], alleviation of the severity of dextran sulfate sodium-induced colitis [15], and antidiabetic effects [16]. However, it has not been well known whether fermented ginseng extracts have antiviral activity, conferring in vivo protection against influenza virus.

In this study, we investigated antiviral effects of fermented ginseng extract samples on influenza viruses. Results in this study demonstrated that fermented red ginseng extracts had an antiviral protective activity against influenza viruses from different subtypes (H1N1, H3N2, H5N1, H7N9) in in vivo mouse models. In vitro cell culture studies suggested mechanistic insights into the antiviral activity of the fermented ginseng extracts. Fermented ginseng products showed higher in vivo antiviral effects against influenza viruses compared to nonfermented ginseng samples.

\section{Materials and Methods}

\subsection{Cells, Viruses, and Ginseng Samples}

Madin-Darby canine kidney (MDCK) cells purchased from ATCC (Manassas, VA, USA) were cultured in Eagle's Minimum Essential Medium (EMEM) and used for microneutralization tests and plaque assays. Subtypes A/Philippines/82 (H3N2), A/California/04/2009 (H1N1pdm), and A/WSN/1933 (H1N1) viruses were kindly provided by Dr. Huan Nguyen, Dr. Richard Webby, and Dr. Yumiko Matsuoka, respectively. The reassortant A/Vietnam/1203/2004 virus (A/VN1203), reverse genetic recombinant $\mathrm{A} / \mathrm{VN} 1203, \mathrm{rgH} 5 \mathrm{~N} 1$ containing HA with polybasic residues removed and NA from A/VN1203, and six internal genes from A/PR/8/1934 (H1N1) was described in our previous study [17]. The reassortant rgH7N9 virus was generated to contain H7 HA and N9 NA genes from A/Shanghai/2013 and six internal genes from A/PR/8/1934 backbone virus using reverse genetics. The H7 HA and N9 NA genes were kindly provided by Dr. García-Sastre. These influenza viruses were propagated in 10-day-old embryonated eggs [18]. The egg allantoic fluids were harvested and stored at $-80{ }^{\circ} \mathrm{C}$ until use. The fermented ginseng extract samples used in this study were obtained from Metabolab Co., Ltd. (Seoul, South Korea). Briefly, the preparation of the fermented ginseng extract samples was carried out by a complex fermentation procedure combined with patented strains of Lactobacillus alimentarius M-2 (KCTC 11054 BP), Leuconostoc mesenteroides M-3 (KCTC 11055 BP), and pectolytic enzymes (Novozymes, Kobenhavn, Denmark) for 7 days (Korean Patent No. KR-1008774890000). The fermentation for preparing fermented ginseng sample A (F.G.A) was processed for the extended time of 7 days for high levels of compound K production, whereas the fermentation time for fermented ginseng sample B (F.G.B) was shortened for 2 days so that the ginsenoside components $(\mathrm{Rb} 1+\mathrm{Rg} 1)$ would be retained above a level of $2.5 \mathrm{mg} / \mathrm{g}$ of ginseng sample. The condition of strains and enzymes was identical for preparation of F.G.A and F.G.B. The components of fermented ginseng extract samples A and B are presented in Table 1. The commercial nonfermented ginseng sample was kindly provided by Korea Ginseng Corporation (Daejeon, Korea). Briefly, fresh roots of the Panax ginseng were washed, steamed at $100{ }^{\circ} \mathrm{C}$ for $2-3 \mathrm{~h}$ and dried. The dried red ginseng roots were boiled in 4-5 volumes of water for $3 \mathrm{~h}$, and the supernatant ginseng extracts were concentrated and manufactured for nonfermented ginseng extract products. 


\subsection{Mice and Treatment}

Wild-type mice (BALB/c and C57BL6) and mutant mice (CD4 T cell-deficient B6.129S6-Cd4 ${ }^{\mathrm{tm} 1 \mathrm{Knw}} / \mathrm{J}$, CD8 T cell-deficient B6.129S2-Cd8atm1Mak/J, B cell-deficient $\mu$ MT B10.129S2(B6)-Ighmtm1Cgn/J, MHCII deficient (B6.129S2-H2dlAb1-Ea/J)) were purchased from the Jackson Laboratory (Bar Harbor, ME, USA). To determine in vivo antiviral effects, $25 \mu \mathrm{L}$ of different strains of influenza viruses were mixed with $25 \mu \mathrm{L}$ of fermented ginseng extract samples A or B and then incubated for $30 \mathrm{~min}$ at $37^{\circ} \mathrm{C}$. The amounts of ginseng samples in the mixtures were in the range of 50-1000 $\mu \mathrm{g}$ doses per mouse. Then, $50 \mu \mathrm{L}$ of virus-ginseng mixtures were intranasally inoculated into naive mice $[19,20]$. For the experiment involving treatment with ginseng after infection, wild-type BALB/c mice were infected with A/WSN $(\mathrm{H} 1 \mathrm{~N} 1)$ influenza virus $\left(1 \times \mathrm{LD}_{50}\right)$ first. After $1 \mathrm{~h}$ postinfection, $1 \mathrm{mg}$ dose of fermented ginseng sample A was intranasally inoculated into the infected mice every hour for five times.

Body weight changes and survival rates of mice were monitored daily after infection. All animal experiments were followed by the instruction of the Institutional Animal Care \& Use Committee (IACUC) of Georgia State University (approved protocol IACUC protocols A14025 on 20 October 2014 and A18001 on 18 September 2017).

\subsection{Lung Viral Titers, Histology and Cytokine ELISA}

Mice were sacrificed at day 6 postinfection with A/Vietnam/1203/2004 (rgH5N1) and bronchoalveolar lavage fluids (BALF), and lung samples were collected from the individual mouse as previously described [21]. Part of the lung samples was fixed with $10 \%$ formalin for $24 \mathrm{~h}$, transferred to the serial of $70-100 \%$ ethanol, and embedded in paraffin. The sections of lung samples were stained with hematoxylin and eosin, and pictures were taken using a microscope (PLYMPUS VS-120 with VISIOMORPH and TISSUNORPH software, Pittsburgh, PA, USA). Dilutions of lung extracts were inoculated in the 11-day-old embryonated chicken eggs. Lung viral titers were determined by measuring hemagglutination activity and calculated using the Reed-Muenchen method. After 2 days of incubation, allantoic fluids $(50 \mu \mathrm{L})$ were collected from the eggs infected with each dilution and mixed with $50 \mu \mathrm{L}$ of chicken red blood cells. The endpoint dilutions were determined after observation of forming the agglutination on the bottom of the V-shape 96-well plates. Levels of cytokines, such as IL-6 and TNF- $\alpha$ in BALF and lung extracts, were determined by ELISA as described [11]. To determine the effect of F.G.A on interaction between antibodies and virus, the 96-well plates were coated with inactivated A/2009/California (H1N1) or A/2004/Vietnam (H5N1) influenza virus overnight, then incubated with $10 \mathrm{mg}$ of F.G.A or nonfermented ginseng for $1 \mathrm{~h}$ at $37^{\circ} \mathrm{C}$. Anti-H1 HA (NR-19866 BEI resource) and Anti-H5 HA (NR-13449 BEI resource) were used as primary antibodies, and the secondary goat anti-mouse IgG (SouthernBiotech CAT NO 1033-05, Birmingham, AL, USA) was used for the ELISA test.

\subsection{Virus Microneutralization and Plaque Assays and Cell Viability Tests in MDCK Cells}

Virus microneutralization assay using MDCK cells was performed as previously described [22]. In brief, influenza virus was mixed with ginseng extract samples, and the mixture was incubated for $1 \mathrm{~h}$ at $37^{\circ} \mathrm{C}$. Then, the virus-ginseng mixture was added to $\left(1 \times 10^{5}\right) \mathrm{MDCK}$ cells and cultivated for $18-22 \mathrm{~h}$ at $37{ }^{\circ} \mathrm{C}$ with $5 \% \mathrm{CO}_{2}$. After discarding the supernatants, the mixtures with MDCK cells were fixed to the 96 -well plate with $80 \%$ acetone for 10 min For the ELISA OD value determination, the primary antibody (anti-NP mouse monoclonal, Chemicon \#MAB8257B, Fisher Scientific, Hampton, $\mathrm{NH}, \mathrm{USA}$ ) and the secondary antibody (goat anti-mouse IgG HRP-conjugated, Southern Biotech \#7100-05) were used. Virus control wells (VC: virus only) and cell control wells (CC: cells only) were set for OD value calculation: " $X^{\prime \prime}=(($ Average of VC wells $)-($ Average of CC wells $)) / 2+($ Average of $C C$ wells). All OD values below " $X$ " were considered as a positive (virus negative) for the neutralizing activity. $\mathrm{TCID}_{50}(50 \%$ tissue culture infective dose) was used to measure the cell infection rate. 
For the plaque forming assays, A/California/2009 (H1N1) and A/Vietnam/1203/2004 (rgH5N1) were mixed with different ginseng samples at a final concentration of $10 \mathrm{mg} / \mathrm{mL}$ for $30 \mathrm{~min}$ at $37^{\circ} \mathrm{C}$. Then, the mixture was incubated with MDCK monolayer cells for $1 \mathrm{~h}$ at $37^{\circ} \mathrm{C}$. After the incubation for $1 \mathrm{~h}$, the virus-ginseng mixture was discarded and the MDCK monolayer was covered with $1.5 \%$ agarose with $2 \times$ DMEM and trypsin. The whole MDCK monolayer with agarose was cultivated for $3-5$ days at $37{ }^{\circ} \mathrm{C}$ with $5 \% \mathrm{CO}_{2}$ and fixed with $4 \%$ formalin for $1 \mathrm{~h}$ after removing the agarose layer [19]. Crystal violet staining solution is often used in such experiments, but it was not required to observe plaque formation. After drying the 6-well plates, plaques were visible and counted.

For cell viability test, $2 \mathrm{~mL}$ of EMEM medium was mixed with different concentrations of F.G.A to make final concentrations of F.G.A to $5 \mathrm{mg}$ and $10 \mathrm{mg} / \mathrm{mL}$. The mixtures were incubated with MDCK monolayer for $6 \mathrm{~h}$. The medium-ginseng mixture was then removed, and cells were washed out by $0.25 \%(w / v)$ trypsin/ $0.53 \mathrm{mM}$ EDTA. Viable cells were counted after staining with $0.4 \%$ trypan blue solution.

\subsection{Hemagglutinin Assay}

Hemagglutination titrations of A/California/2009 (H1N1) and A/Vietnam/1203/2004 (H5N1) strains were determined using a standard method [23]. Fermented ginseng extract samples $(25 \mu \mathrm{L})$ were mixed with $25 \mu \mathrm{L}$ of $4-8 \mathrm{HA}$ units of virus at $37^{\circ} \mathrm{C}$ for $30 \mathrm{~min}$. The virus-ginseng mixture was then mixed with $50 \mu \mathrm{L} 0.5 \%$ chicken red blood cell and incubated for $1 \mathrm{~h}$ at room temperature. A negative control (virus only) and a positive control (no virus) were set in this assay.

\subsection{Neuraminidase Assay}

NA-specific inhibition activity by enzyme-linked lectin assays using virus substrates has been well reported in previous studies [24-27]. Fetuin proteins (Sigma, St. Louis, MO, USA, cat\# F3385) were coated on the 96-well plate. Before adding viruses to the plate, $2 \times$ virus $(25 \mu \mathrm{L})$ was mixed with a $2 \times$ ginseng sample $(25 \mu \mathrm{L})$ and incubated at $37^{\circ} \mathrm{C}$ for $30 \mathrm{~min}$. The virus-ginseng mixture was incubated in the plate for $2 \mathrm{~h}$. After washing the unbound viruses, HRP conjugate of lectin from Arachis hypogaea peanut (Sigma, cat\# L6135-1MG) was added and then incubated for $2 \mathrm{~h}$. O-phenylenediamine dihydrochloride (OPD) (Sigma, cat\# P8287) was used to check the color development, and plates were finally read in $450 \mathrm{~nm}$ after stopping the reaction.

\subsection{Statistical Analysis Methods}

A two-tailed student's $t$-test was used to determine whether the two different groups showed statistical significance. When $p$ value was less than 0.05 , it was considered as significant.

\section{Results}

\subsection{Fermented Ginseng Samples Exhibit Higher Antiviral Protection against Influenza Virus than Nonfermented Ginseng}

Orally taken ginseng supplements are digested and fermented in the intestines, producing active ingredients such as ginsenosides, including compound $\mathrm{K}$. We tested whether fermented ginseng samples would have antiviral in vivo protection against a lethal dose of influenza virus infection. The red ginseng extracts were in vitro fermented with a mixture of bacteria and enzymes, and the product compounds were characterized as shown in Table 1. In vitro fermentation of ginseng samples generated new ginsenoside saponin compounds (F1, F2, PPT, CK, Rh2, PPD) but resulted in lower levels of total ginsenosides (Table 1). The fermented ginseng sample A (F.G.A) contained higher levels of new ginsenoside compounds (F1, F2, PPT, CK, Rh2, PPD) compared to those in the fermented ginseng sample B (F.G.B) (Table 1). 
Table 1. Components of ginseng samples (mg/g).

\begin{tabular}{cccc}
\hline Ginsenosides & Red Ginseng Extracts & Fermented Ginseng A & Fermented Ginseng B \\
\hline Rg1 & 1.36 & 0.60 & 1.27 \\
Re & 1.43 & 0.49 & 0.87 \\
Rf & 1.02 & 0.29 & 0.13 \\
Rb1 & 6.86 & 0.95 & 2.74 \\
Rc & 2.76 & 0.04 & 0.05 \\
Rg2 & 1.03 & 0.65 & 0.25 \\
Rh1 & 1.02 & 0.58 & 0.19 \\
Rb2 & 2.46 & 0.02 & 0.26 \\
Rb3 & 0.57 & 0.01 & 0.02 \\
F1 & - & 0.28 & 0.17 \\
Rd & 0.82 & 0.62 & 0.75 \\
F2 & - & 0.55 & 0.47 \\
Rg3 & 1.51 & 0.62 & 0.54 \\
PPT & - & 0.88 & 0.33 \\
CK & - & 4.19 & 1.69 \\
Rh2 & - & 1.49 & 0.43 \\
PPD & - & 2.13 & 0.93 \\
Total ginsenosides & $21.0 \mathrm{mg} / \mathrm{g}$ & $14.39 \mathrm{mg} / \mathrm{g}$ & $11.09 \mathrm{mg} / \mathrm{g}$ \\
\hline
\end{tabular}

CK: compound K, PPD: protopanaxadiol, PPT: protopanaxatriol

To test the antiviral protective effects of the fermented ginseng samples $A$ and $B$, groups of mice (wild-type BALB/c) were intranasally infected with a lethal dose $\left(1.5 \mathrm{LD}_{50}\right)$ of rgH5N1 virus alone or rgH5N1 virus mixed with the fermented ginseng extracts of A or B (F.G.A or F.G.B) or nonfermented ginseng (non-F.G) extract. High and moderate doses (500, $250 \mu \mathrm{g}$ ) of F.G.A and high dose (500 $\mu \mathrm{g})$ of F.G.B or non-F.G were first tested (Figure 1). In the group with F.G.A, at doses of either $500 \mu \mathrm{g}$ or $250 \mu \mathrm{g}$, none of the mice showed weight loss after infection with rgH5N1 virus (F.G.A 500, $250 \mu$, Figure 1A). However, in the group with fermented ginseng B or nonfermented ginseng $(500 \mu \mathrm{g})$, all mice began to lose weight from day 3 postinfection (F.G.B, Non-F.G, $500 \mu$ g, Figure 1A). From day 7 or day 9, all mice from fermented ginseng $B$ or nonfermented ginseng groups began to recover, respectively, while all mice in the rgH5N1 virus-only infection group died by day 8 postinfection (Figure 1A).

Viral replication during the primary infection of mice induces immune responses of antibodies and cross protective T cells. Protection by inhibiting complete viral replication does not induce virus-specific immune responses. Next, we examined whether the infected mice generated rgH5N1-specific antibodies. We collected the immune sera from all mice from the first rgH5N1 virus infection and determined the induction of antibody responses due to the viral replication. The groups of mice with F.G.B, non-F.G $(500 \mu \mathrm{g})$, and naive mice that survived from a sublethal dose of rgH5N1 virus infection showed high levels of virus-specific antibody responses due to influenza viral replication. By contrast, the fermented ginseng sample A groups (F.G.A 500, $250 \mu \mathrm{g}$ ) showed no significant virus-specific antibodies, suggesting complete protection against viral replication (Figure 1C,D,E).

We then applied the secondary infection with $3 \mathrm{LD}_{50}$ of $\mathrm{rgH} 5 \mathrm{~N} 1$ to those groups that survived from the first infection (Figure 1B). Due to the complete protection during the primary infection by the antiviral activity of F.G.A, no antibody responses were produced and the mice that survived the virus mixture of F.G.A (500, $250 \mu \mathrm{g})$ showed significant body weight loss (15-20\%) during the secondary infection; this indicated complete protection only during primary infection. Nonetheless, compared to the naïve infection group (Figure 1B, naïve rgH5N1 only), all the mice from F.G.A (500, $250 \mu \mathrm{g}$ ) survived and showed less body weight loss. Meanwhile, the mouse F.G.B and nonfermented ginseng $(500 \mu \mathrm{g})$ groups did not display body weight loss. As expected, from the levels of rgH5N1 virus specific antibodies and disease of weight loss during the primary virus infection, these mice (F.G.B $500 \mu \mathrm{g}$, non-FG $500 \mu \mathrm{g}$ ) developed strong immunity. 


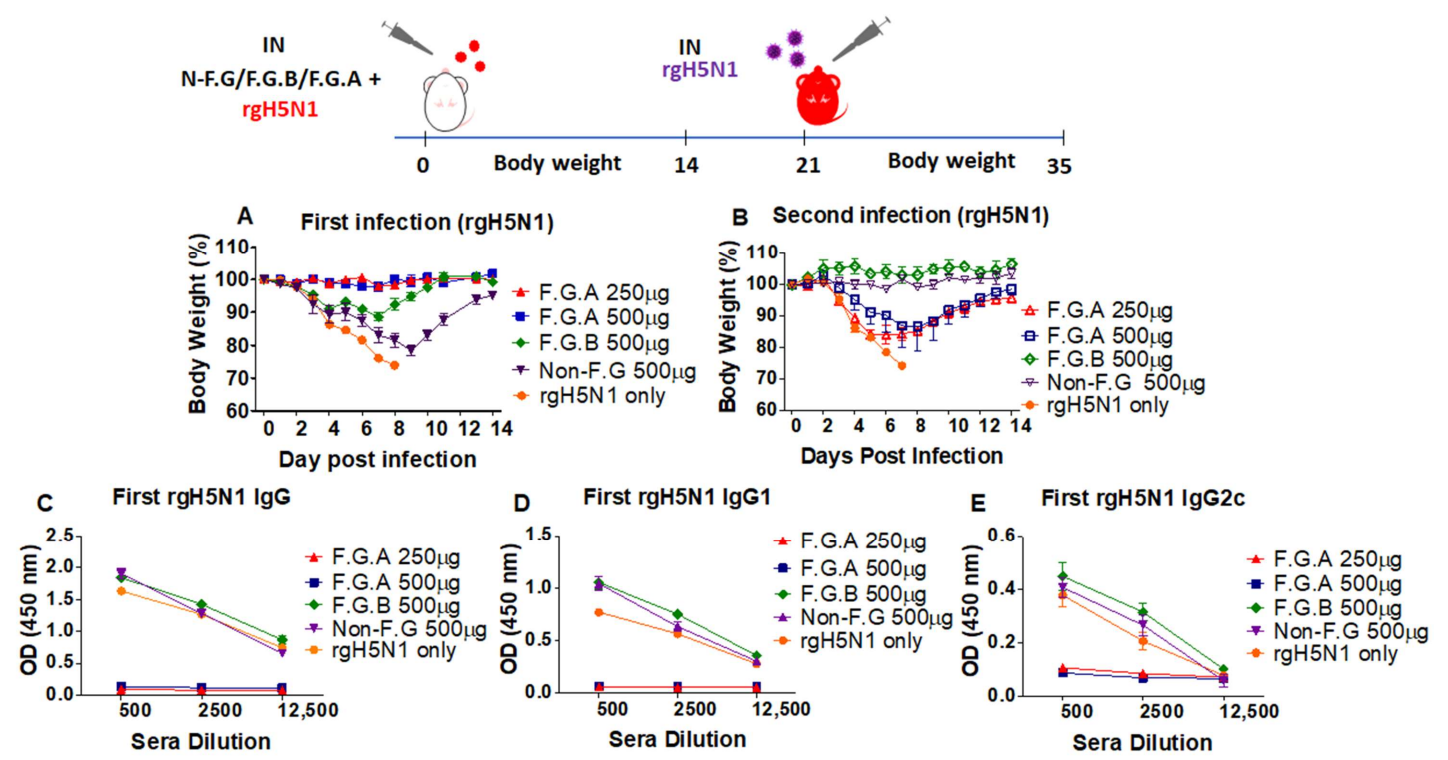

Figure 1. Fermented ginseng sample A showed higher antiviral protective activity against influenza viruses. Groups of mice ( $n=5$, wild-type BALB/c mice) were intranasally (IN) infected with a mixture of $1.5 \mathrm{LD}_{50} \mathrm{~A} /$ Vietnam/1203/2004 (rgH5N1) and fermented ginseng sample A or B at different doses $(250 \mu \mathrm{g}$ and $500 \mu \mathrm{g})$. After 14 days of body weight monitoring, the serum sample was collected to detect the levels of IgG and IgG isotypes using a ELISA method. The mice that survived from the first $\mathrm{rgH} 5 \mathrm{~N} 1$ infection were challenged again with a lethal dose of $\mathrm{rgH} 5 \mathrm{~N} 1\left(3 \mathrm{LD}_{50}\right)$. (A) Body weight change after the first infection ( $\mathrm{rgH} 5 \mathrm{~N} 1)$ and $(\mathrm{B})$ body weight change after the second infection (rgH5N1). (C) rgH5N1-specific IgG, (D) IgG1, and (E) IgG2a after the first infection. F.G.A: rgH5N1 virus + fermented ginseng sample A; F.G.B: rgH5N1 virus + fermented ginseng sample B; non-F.G: not fermented ginseng; rgH5N1 only: virus infection without ginseng samples.

\subsection{Protected Mice with Fermented Ginseng and rgH5N1 Influenza Virus Inoculation Develops Immunity against Virus Infection in Future}

Since the fermented ginseng extract sample A showed better antiviral protection activity, we further investigated whether a lower dose of sample A would exhibit such an antiviral effect without weight loss and acquire immunity against secondary infection. In this set of experiments, a different genetic background of C57BL/6 mice was used to test in vivo antiviral activity of ginseng samples. Different doses of F.G.A $(100,50$, and $20 \mu \mathrm{g})$ with a high dose of rgH5N1 virus were applied to the wild-type C57B/ 6 mice $(n=5)$. As a positive control, a high dose (500 $\mu \mathrm{g})$ of F.G.A was also included in this experiment. Moderate to low doses (100 and $50 \mu \mathrm{g})$ of F.G.A showed $100 \%$ protection without displaying weight loss, as observed in the high dose $(500 \mu \mathrm{g})$ F.G.A group. However, the lowest dose $(20 \mu \mathrm{g})$ of F.G.A did not show any antiviral protective effect against the high dose $\left(10 \mathrm{LD}_{50}\right)$ of rgH5N1 virus (Figure 2A, F.G.A $20 \mu \mathrm{g}$ ). As a negative control, mice from the group of nonfermented ginseng also died at day 7 postinfection with rgH5N1 virus (Figure 2A, non-F.G $500 \mu \mathrm{g}$ ).

As in the $500 \mu \mathrm{g}$ F.G.A group, the treatment with mixture of $100 \mu \mathrm{g}$ F.G.A and rgH5N1 virus $\left(10 \mathrm{LD}_{50}\right)$ did not induce virus-specific antibodies (Figure 2C,D,E) during infection, suggesting complete inhibition of viral replication and protection. As expected, the mice from these $100 \mu \mathrm{g}$ and $500 \mu \mathrm{g}$ F.G.A groups that survived during primary infection were not protected during the secondary infection (Figure 2B). However, the dose of $50 \mu \mathrm{g}$ F.G.A-treated mouse group showed protection without body weight loss (Figure 2A), induced rgH5N1 virus-specific antibodies during primary infection (Figure 2C,D,E), and was protected without weight loss during the secondary infection $\left(15\right.$ LD $_{50}$ H5N1, Figure 2B). These results suggest that the F.G.A protected the mice against influenza virus in a dose-dependent manner and that treatment with an optimal dose of fermented ginseng and virus provides protection against primary infection and induces immunity against secondary infection. 


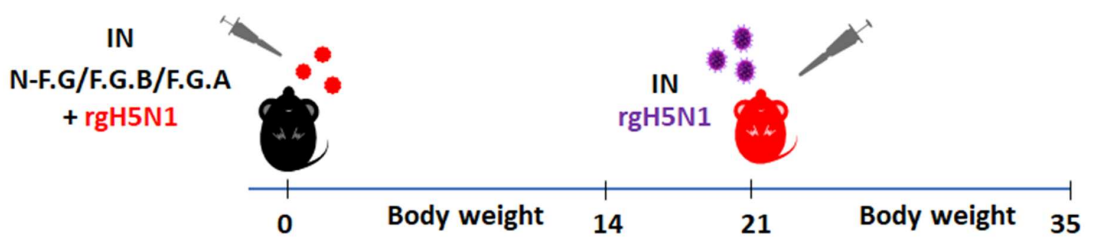

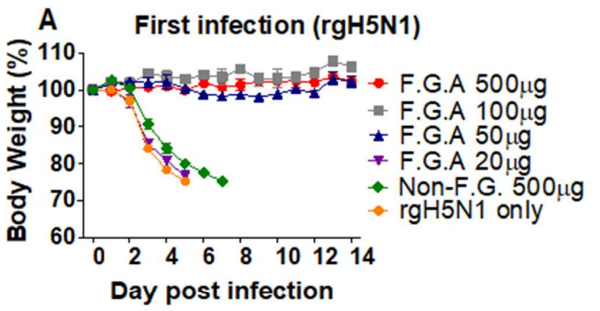
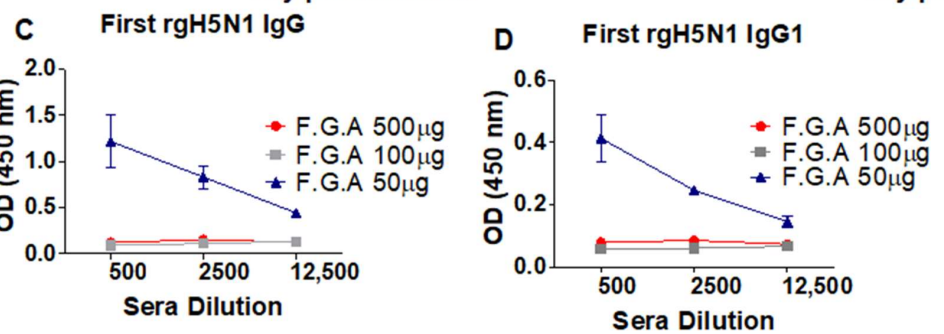

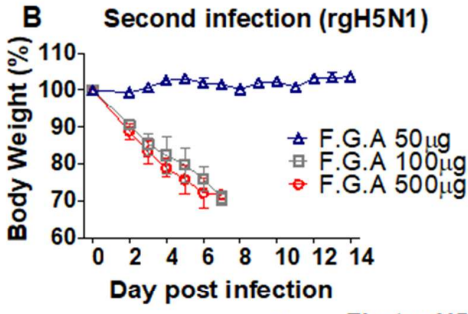

E First rgH5N1 IgG2C

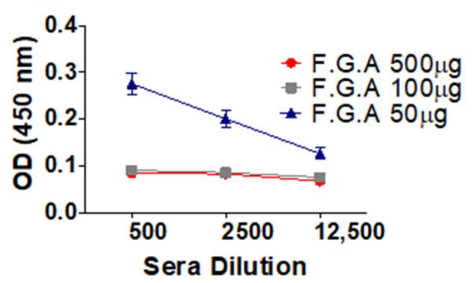

Figure 2. Low dose of fermented ginseng extract sample A provided protection against rgH5N1 influenza virus during primary and secondary infection. Groups of mice ( $n=5$, wild-type C57BL/6) mice were intranasally (IN) infected with a mixture of 10 LD $_{50}$ of A/Vietnam/1203/2004 (rgH5N1) virus and fermented ginseng sample A or B at different doses $(20,50,100,500 \mu \mathrm{g})$. After 14 days of body weight monitoring, the serum sample was collected to detect the levels of IgG and IgG isotypes using an ELISA method. The mice that survived from the first infection were challenged again with rgH5N1 (10 LD 50$)$. (A) Body weight change after the first infection (10 LD 50, rgH5N1) and (B) body weight change after the second infection (15 LD $50, \mathrm{rgH} 5 \mathrm{N1}$ ). (C) rgH5N1-specific IgG, (D) IgG1, and (E) IgG2c after the first infection. F.B.A: rgH5N1 virus + fermented ginseng sample A; F.G.B: H5N1 virus + fermented ginseng sample B; rgH5N1 only: virus infection without ginseng samples.

\subsection{Fermented Ginseng Sample Has Antiviral Protective Effects against H3N2 Influenza Virus in CD8-Deficient Mice}

$\mathrm{CD}^{+} \mathrm{T}$ cell plays an important role in viral clearance and recovery upon influenza virus infection [28]. Because there were no rgH5N1 specific antibodies induced in the previous experiments (Figures 1 and 2), we used CD8 T cell-deficient (CD8 KO) mice $(n=3)$ to investigate whether CD8 ${ }^{+}$ $\mathrm{T}$ cells were required for conferring protection virus by fermented ginsengs. The fermented ginseng sample A exhibited a similar pattern of protection against A/Philippines/82(H3N2) in CD8 KO mice. Both groups of CD8 KO mice with mixture of H3N2 virus and $500 \mu \mathrm{g}$ and 250 of F.G.A were fully protected against body weight loss (Figure 3A). The mice from these two groups did not induce virus-specific antibodies (Figure $3 \mathrm{C}, \mathrm{D}, \mathrm{E}$ ) and were not able to develop sufficient immunity against follow-up infection with the same H3N2 virus, as evidenced by significant body weight loss ( 15\%). This is despite the groups showing better protection than naïve mice with H3N2 infection, which resulted in over $\sim 20 \%$ weight loss (Figure $3 B$ ). Compared to the F.G.A groups, virus inoculation with $500 \mu \mathrm{g}$ of F.G.B showed less protection against H3N2 virus, resulting in $5-10 \%$ body weight loss and the induction of high levels of H3N2 virus-specific antibodies (Figure 3C,D,E). As expected from the levels of IgG antibodies, this $500 \mu \mathrm{g}$ F.G.B group was well protected during secondary infection H3N2 virus (Figure $3 \mathrm{~B}$ ). These results suggest that CD8 $\mathrm{T}$ cell is not required for fermented ginseng's antiviral in vivo protection against influenza virus. 

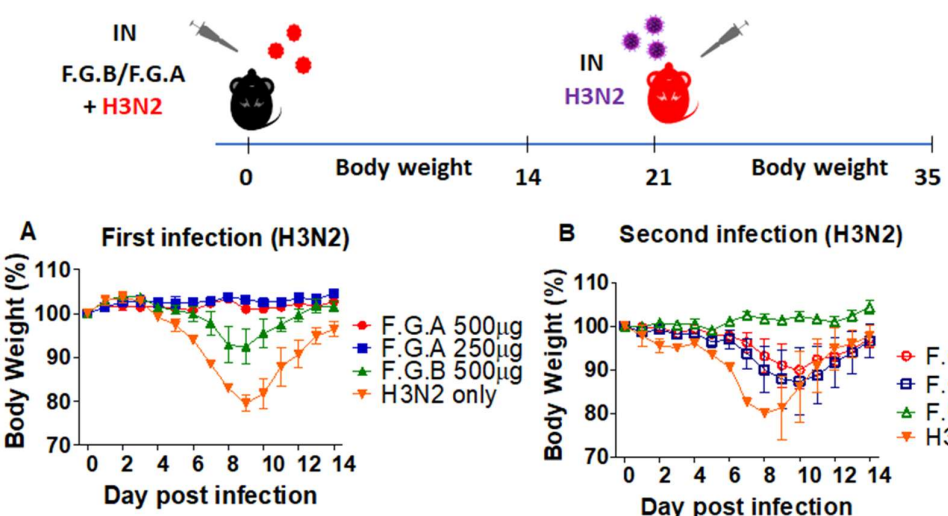

B Second infection (H3N2)
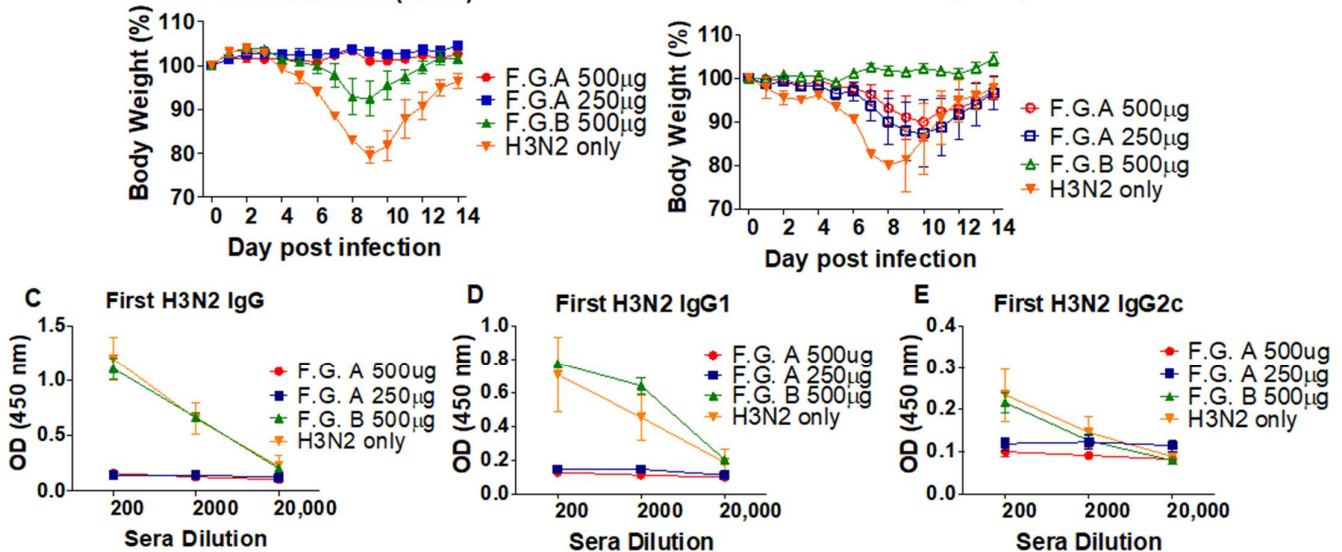

Figure 3. Fermented ginseng sample A showed higher antiviral protective activity against $1.0 \mathrm{LD}_{50}$ H3N2 influenza viruses. Groups of mice ( $n=5$, CD8 T cell-deficient, CD8KO) were intranasally (IN) infected with a mixture of $1 \mathrm{LD}_{50}$ of A/Philippines/82 (H3N2) virus and fermented ginseng sample A or B at different doses (250 and $500 \mu \mathrm{g}$ ). After 14 days of body weight monitoring, the serum sample was collected to detect the levels of IgG and IgG isotypes after the first infection using an ELISA method. The mice that survived from $\mathrm{H} 3 \mathrm{~N} 2$ virus infection were challenged with homogenous virus $\left(1.5 \mathrm{LD}_{50}\right.$, H3N2). (A) Body weight change after the first infection (H3N2) and (B) body weight change after the second infection (H3N2). (C) H3N2 specific IgG, (D) IgG1, and (E) IgG2c after the first infection. F.G.A: H3N2 virus + fermented ginseng sample A; F.G.B: H3N2 virus + fermented ginseng sample B; H3N2 only: virus infection without ginseng samples.

\subsection{Antiviral Protection by Fermented Ginseng Extract Is Observed Regardless of Influenza Strains and in Severe Immune-Deficient Condition}

We determined in vivo antiviral protection of fermented ginseng extract against rgH7N9 reassortant virus. As shown in Figure 4A, $250 \mu \mathrm{g}$ of fermented ginseng sample A protected wild-type C57BL/ 6 mice that were inoculated with ginseng and rgH7N9 virus. Thus, the antiviral protection by the fermented ginseng samples was observed with rgH5N1 virus, H3N2 virus, and rgH7N9 virus, suggesting universal protection regardless of the type of influenza strain.

Induction of antibodies is known to be the most relevant immune correlate conferring protection against influenza virus. To test whether fermented ginseng sample A inoculation with H1N1 virus would have antiviral protective effects in a B cell-deficient mice, a $\mu \mathrm{MT}$ mouse model was used with a similar protocol as described in previous sections (Figure 4B). The infection of $\mu$ MT mice $(n=3)$ with the mixture of fermented ginseng sample A and A/California/2009 (H1N1) resulted in complete protection as observed in wild-type mice. Similar results were observed in MHC-II knockout mice. As shown in the Figure 4C, inoculation with rgH5N1 virus and fermented ginseng sample A resulted in complete protection against a lethal virus dose in MHC-II knockout mice. In vivo antiviral protection in B cell-deficient $\mu \mathrm{MT}$ or MHC-II-deficient mice was consistently observed, supporting the conclusion that fermented ginseng samples can inhibit viral replication to a level below the detection limit. 


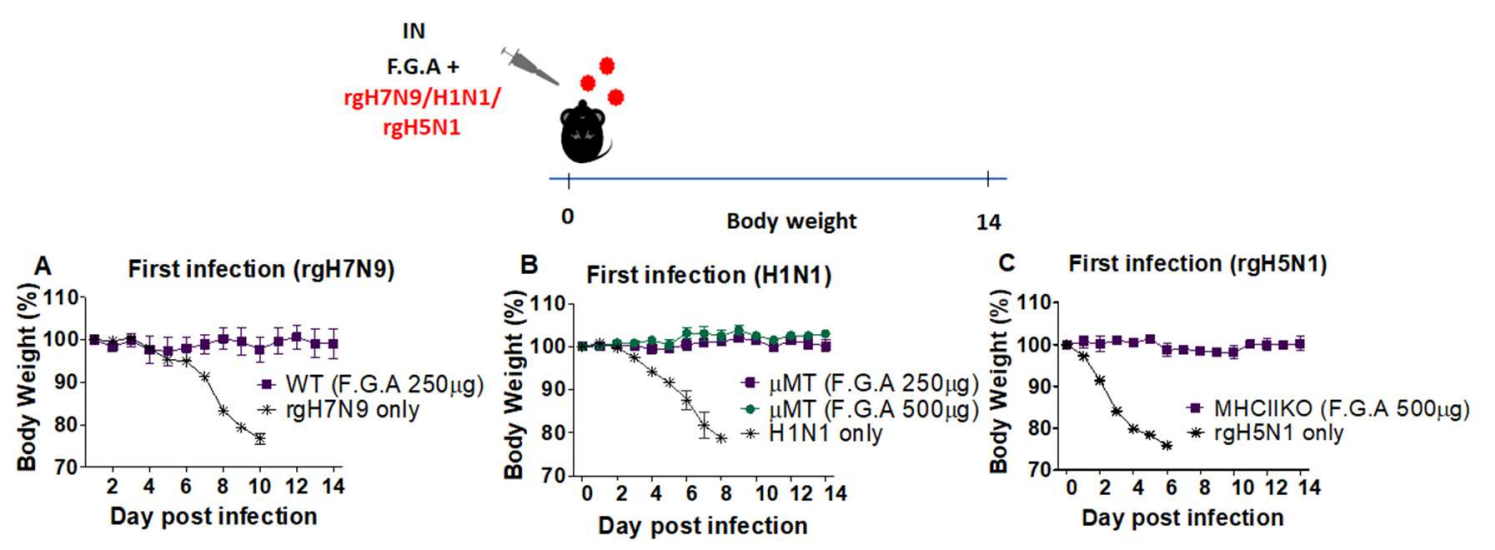

Figure 4. Fermented ginseng sample A had antiviral protective effects against H1N1 or rgH5N1 influenza virus even in severe immune-deficient mice. Groups of wild-type $(n=3, \mathrm{C} 57 \mathrm{BL} / 6)$ and mutant mice ( $n=3$, B cell-deficient and MHCIIKO) were intranasally (IN) infected with a mixture of virus ( $\left.2 \mathrm{LD}_{50}\right)$ and fermented ginseng sample A at different doses (250 and $\left.500 \mu \mathrm{g}\right)$. Body weight changes were monitored for 14 days after the infection. (A) A/Shanghai/2013 (rgH7N9, 2 LD 50 ) virus inoculation in wild-type mice; (B) A/California/2009 (H1N1) virus inoculation in $\mu$ MT (B cell deficient) mice; (C) A/Vietnam/1203/2004 (rgH5N1) virus inoculation in MHCIIKO mice. F.G.A: fermented ginseng sample A; rgH7N9 only: virus infection without ginseng samples; H1N1 only: virus infection without ginseng samples; rgH5N1 only: virus infection without ginseng samples.

\subsection{Inoculation of Mice with Fermented Ginseng Extract Samples and Virus Together Inhibits Viral Replication} and Lung Inflammation

We further determined the efficacy of antiviral protection in wild-type mice (Figure 5) and CD4KO mice (Supplementary Figures S1 and S2). As expected, the F.G.A $250 \mu \mathrm{g}$ group showed more effective protection as evidenced by no sign of weight loss (Figure 5A, Supplementary Figure S2A) compared to F.G.B $250 \mu \mathrm{g}$ group displaying $5-10 \%$ weight loss at day 6 postinoculation (Supplementary Figure S2A). Ginseng-only treatment did not have any effects on weight changes in mice without infection. By contrast, the group receiving $1 \mathrm{mg}$ F.G.A treatment postinfection displayed 10-15\% weight loss (Figure 5A. F.G.A $1 \mathrm{mg}$, postinfection), suggesting no protective effects on postinfection. Then, we determined lung viral titers as an in vivo antiviral activity of controlling viral replication at 6 days after inoculation with fermented ginseng extracts and virus (Figure 5B-D). The untreated naïve mice inoculated with WSN H1N1 virus (Figure 5B) and rgH5N1 virus (Supplementary Figure S2B) resulted in the highest viral titers of viral replication in the lung (over $7.4 \times 10^{5}$ titers of egg infectious units). Treatment of F.G.A $(1 \mathrm{mg})$ postinfection resulted in high lung viral titers, similar to the untreated naïve mice (Figure 5B). Mixed virus inoculation with the fermented ginseng sample B lowered lung viral titers to $1.5 \times 105 \mathrm{egg}$ infectious units (Supplementary Figure S2B). Nonetheless, viral replication was substantially high in the group of mice with fermented ginseng sample B. Lung viral titers were below the detection limit in the group of mice with F.G.A (Figure 5B, Supplementary Figure S2B), indicating that the fermented ginseng sample A completely inhibited lung viral replication after coinoculation with influenza virus.

To better understand the protective effects on preventing inflammatory disease, we determined proinflammatory cytokine levels in the lung extracts at day 6 postinoculation with ginseng samples and WSN H1N1 or rgH5N1 virus. Wild-type mice infected with WSN H1N1 virus only and ones that received $1 \mathrm{mg}$ of ginseng postinfection showed high levels of inflammatory cytokines (IL-6) in the lung (Figure 5C). Mice infected with a mixture of rgH5N1 virus and fermented ginseng sample B displayed lower but substantial levels of inflammatory IL- 6 and TNF- $\alpha$ cytokine in lung and BALF (Supplementary Figure S2C-F). The fermented ginseng sample A group almost completely prevented the induction of proinflammatory cytokines, similar to those in uninfected mice. Therefore, these 
results suggest that fermented ginseng sample A prevented the induction of inflammatory cytokines by inhibiting influenza virus replication.

Influenza virus infection causes severe lung inflammation with high infiltrating cells in the airways and parenchymal tissues, as shown in our histopathology pictures (WSN H1N1 virus, Figure 5D; rgH5N1 virus, Supplementary Figure S2G). At day 6 postinoculation, lung tissue sections in each group were examined for their histopathology. Wild-type mice inoculated with A/WSN H1N1 virus and then treated with $1 \mathrm{mg}$ fermented ginseng sample A or CD4KO mice inoculated with the mixture of fermented ginseng sample B and virus showed a substantial level of lung inflammation, similar to the mice with naive virus infection (Figure 5D; Ginseng B, Supplementary Figure S2G). The group of mice with fermented ginseng sample $A$ and virus infection prevented the induction of lung histopathology at day 6 postinoculation, similar to the uninfected mouse lungs (F.G.A, Figure 5D; Ginseng A, Supplementary Figure S2G).

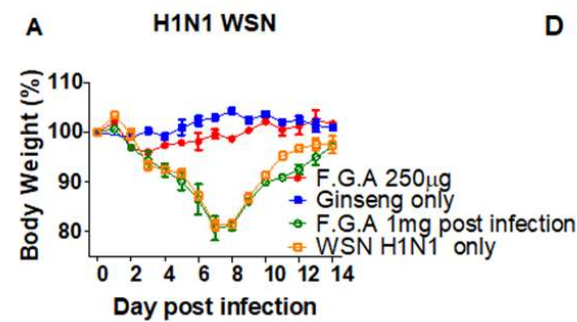

D F.G.A WSN H1N1 Only

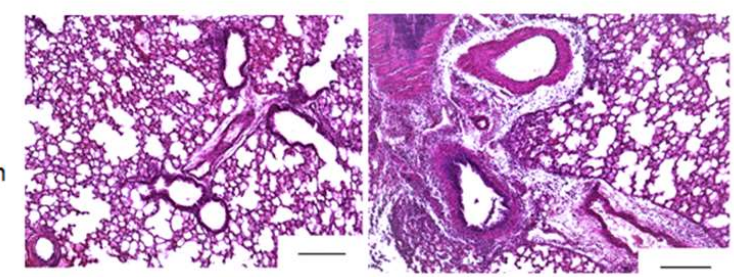

B Lung viral titers

C Lung IL-6

F.G.A
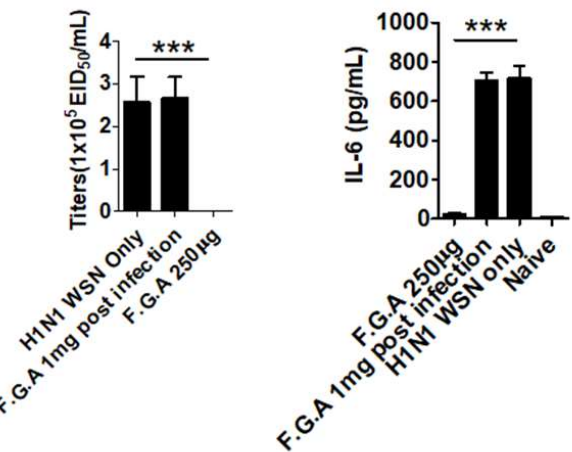

1mg post infection Mock

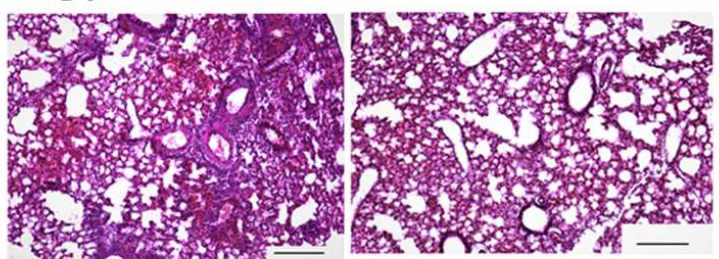

Figure 5. In vivo protection against A/WSN/1933 (H1N1) virus in wild-type BALB/c mice after inoculation with a mixture of fermented ginseng extracts and the virus. Groups of mice $(n=5)$ were infected with a mixture of A/WSN H1N1 virus and fermented ginseng sample A (250 $\mu \mathrm{g})$. Lung viral titers were determined in the lung extracts at day 6 postinfection. (A) F.G.A $250 \mu \mathrm{g}$ : mixed $250 \mu \mathrm{g}$ of F.G.A with A/WSN $\left(1 \times \mathrm{LD}_{50}\right)$ influenza virus; Ginseng only: no WSN virus, just mock infection with $1 \mathrm{mg}$ F.G.A; F.G.A $1 \mathrm{mg}$ postinfection: mice infected with WSN H1N1 first, treated with $1 \mathrm{mg}$ F.G.A one hour postinfection, then treated with $1 \mathrm{mg}$ every $1 \mathrm{~h}$, for five times; H1N1 WSN only: virus infection only. (B) Lung viral titers from the mice at day 6 postinfection. (C) ELISA for IL-6 in lung. (D) Lung histopathology. Mock: no virus, no ginseng; F.G.A: F.G.A 1 mg postinfection; WSN H1N1 only: same as the description above. Magnification: $100 \times$, Scale bars: $50 \mu \mathrm{m}$. Ginseng only: inoculation with ginseng, no viruses. ${ }^{* * *}$ indicates statistical significance, $p<0.0005$ between F.G.A and comparing groups.

\subsection{The Mice That Survive Primary Virus Inoculation with Fermented Ginseng Extract Samples Develop} Immunity against Heterosubtypic Secondary Virus

We found that neither $\mathrm{B}$ cells nor $\mathrm{CD} 8^{+} \mathrm{T}$ cells were required for in vivo antiviral activity by fermented ginseng extract samples (Figure 4). Next, we tested whether CD4 T cells would be needed for antiviral protection by fermented ginseng extract samples. A similar pattern of in vivo antiviral protection was observed in CD4 $\mathrm{T}$ cell-deficient $(\mathrm{CD} 4 \mathrm{KO})$ mice that were intranasally inoculated with 
rgH5N1 virus and fermented ginseng extract samples (Supplementary Figure S1A). As expected, the F.G.A $(250 \mu \mathrm{g}, 500 \mu \mathrm{g}) \mathrm{CD} 4 \mathrm{KO}$ mouse groups showed protection without weight loss, whereas the F.G.B $(250 \mu \mathrm{g}, 500 \mu \mathrm{g})$ CD4KO mice displayed moderate weight loss (8-15\%), which was lower than the weight loss in untreated CD4KO mice (18-22\%).

The mice that survived from the primary virus ( $\mathrm{rgH} 5 \mathrm{~N} 1)$ inoculation with fermented ginseng samples were exposed to the secondary H3N2 virus infection with an antigenically different subtype in the absence of additional ginseng treatment (Supplementary Figure S1B). The F.G.B $250 \mu \mathrm{g}$ treated CD4KO mice that showed an average of $8-9 \%$ weight loss during primary infection exhibited heterosubtypic protection against H3N2 virus without weight loss (Figure 5B). This secondary protection against $\mathrm{H} 3 \mathrm{~N} 2$ virus appears to be due to immunity developed during primary rgH5N1 virus infection. Significant levels of IgG, IgG1, and IgG2c antibodies reactive to $\mathrm{rgH} 5 \mathrm{~N} 1$ virus were observed in the F.G.B $(250 \mu \mathrm{g}, 500 \mu \mathrm{g})$ CD4KO mouse groups but not in the F.G.A $(250 \mu \mathrm{g}, 500 \mu \mathrm{g})$ CD4KO mice (Supplementary Figure S1C-E). It is likely that the doses-250 $\mu \mathrm{g}, 500 \mu \mathrm{g}-\mathrm{of}$ F.G.A had more potent antiviral activity, completely inhibiting viral replication to limit the development of immunity. During the secondary infection with H3N2 virus, this $250 \mu \mathrm{g}$ F.G.A group showed significant body weight loss $(15 \%)$ and then recovered; this was worse than the F.G.B $500 \mu \mathrm{g}$ dose group, which saw a 5-6\% weight loss and slightly better than the one observed in naïve infection, which showed 18-19\% weight loss. By contrast, the $500 \mu$ g F.G.A group that was protected against rgH5N1 virus without weight loss displayed severe weight loss of over $20 \%$.

\subsection{Fermented Ginseng Extract Shows In Vitro Antiviral Activity against Influenza Virus}

Since fermented ginseng extract has in vivo antiviral protection against the influenza virus, we determined whether this ginseng sample has antiviral activity in vitro. The fermented ginseng sample B $(10 \mathrm{mg} / \mathrm{mL})$ only inhibited $10-15 \%$ of viral infection of H1N1, H3N2, and rgH5N1, as determined by the microneutralization method (Figure $6 \mathrm{~A}$ ). In comparison, $10 \mathrm{mg} / \mathrm{mL}$ of sample A neutralized most of the virus of $\mathrm{H} 1 \mathrm{~N} 1, \mathrm{H} 3 \mathrm{~N} 2$, and $\mathrm{rgH} 5 \mathrm{~N} 1$, so influenza virus could not properly replicate in MDCK cells.

The anti-influenza virus activities of fermented ginseng extract against $\mathrm{H} 1 \mathrm{~N} 1$ and $\mathrm{rgH} 5 \mathrm{~N} 1$ were further examined by a plaque assay. As shown in Figure $6 \mathrm{~B}, 10 \mathrm{mg} / \mathrm{mL}$ fermented sample A reduced more than $95 \%$ of plaque-forming units in $\mathrm{H} 1 \mathrm{~N} 1$ virus, while fermented sample B reduced about $70 \%$ of the plaques.

Different incubation time of H1N1 virus with sample A and B prior to infection was tested (Figure 6C). In the figure, 0 min and 5 min of incubating time of sample A reduced 20-25\% of plaques. Extended incubation time of $20 \mathrm{~min}$ reduced more than $60 \%$ of forming plaques. Although the sample $B$ had less inhibitive ability, it also reduced plaques as the incubation time was extended.

We also investigated whether fermented ginseng extract would exhibit inhibitory effects on influenza virus plaque formation upon treatment after MDCK cells had been infected with influenza virus. Approximately $25 \%$ and 50\% reduction in plaques were observed with 3 and $6 \mathrm{~h}$ incubation, respectively, of $10 \mathrm{mg} / \mathrm{mL}$ sample A with MDCK cells that were infected with H1N1 or rgH5N1 virus prior to ginseng sample treatment (Figure 6D). Fermented ginseng sample B treatment postinfection was less effective in reducing viral plaques (25-35\%) than sample A.

Next, we determined the effects of fermented ginseng extract on hemagglutination and neuraminidase activity and on antibody binding to the virus. We found $10 \mathrm{mg} / \mathrm{mL}$ of F.G.A significantly decreased the capture ability of primary antibody of anti-H1 HA or anti-H5 HA to the coated H1N1 or H5N1 on 96-well plate, respectively (Figure 6E,F). Meanwhile, high doses $(10 \mathrm{mg} / \mathrm{mL}$ ) of fermented ginseng sample A (but not sample B) prevented 4 HA units of H1N1 and H5N1 HA-mediated hemagglutination activity (Supplementary Figure S3). As shown in Figure 6G, $20 \mathrm{mg} / \mathrm{mL}$ of fermented ginseng sample A exhibited inhibitory effects on neuraminidase activity of $\mathrm{rgH} 5 \mathrm{~N} 1$ virus, whereas ginseng sample B did not show such neuraminidase inhibitory activity. 
We also tested the cytotoxicity of F.G.A in vitro and in vivo. Different concentrations of F.G.A were added to $2 \mathrm{~mL}$ of EMEM medium at final concentrations of F.G.A $5 \mathrm{mg}$ and $10 \mathrm{mg}$, respectively. As shown in Figure $6 \mathrm{H}, 5 \mathrm{mg}$ and $10 \mathrm{mg} / \mathrm{mL}$ of F.G.A had no impact on cell viability. Meanwhile, mice that were intranasally treated with $1 \mathrm{mg}$ of F.G.A maintained the bodyweight during 14 days of monitoring (Figure 5A, ginseng only).
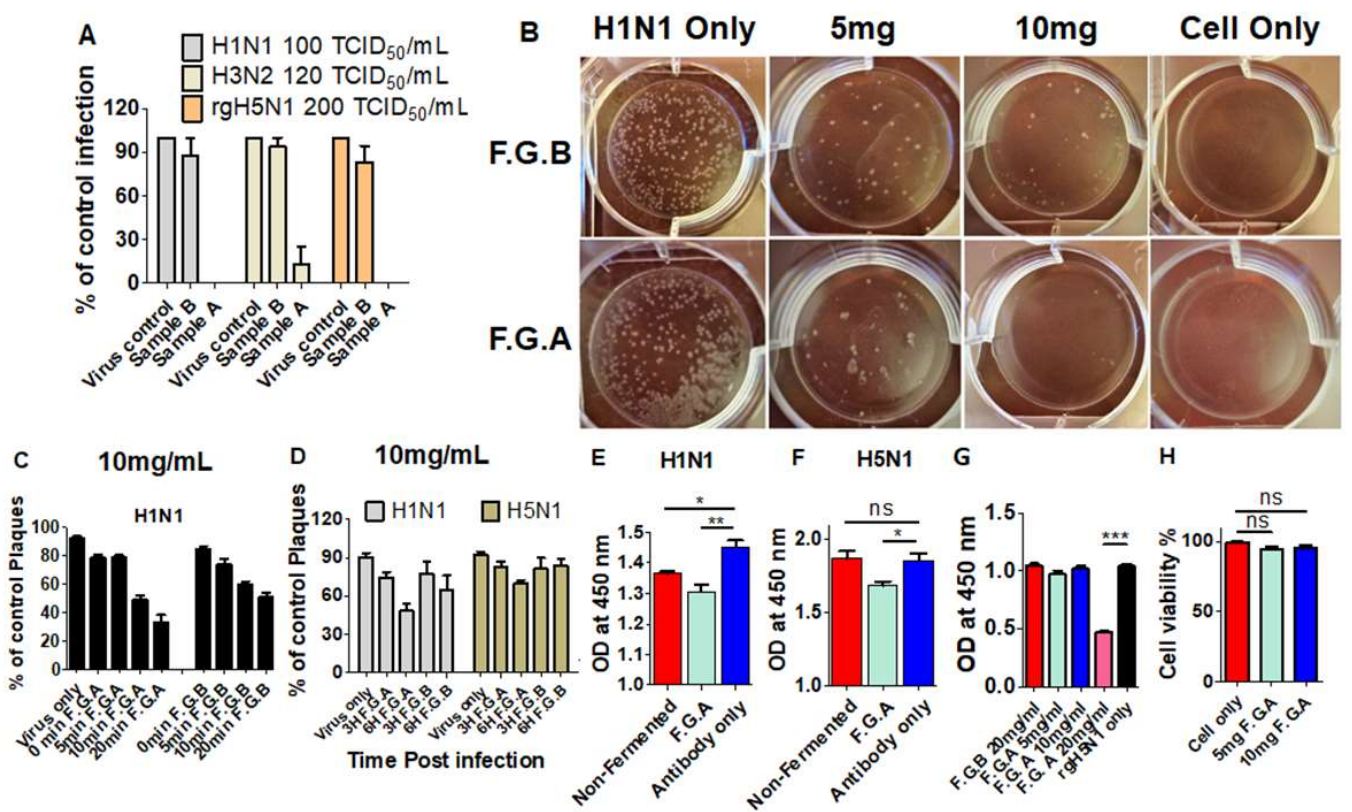

Figure 6. Fermented ginseng extract sample A had antiviral activity against influenza virus in vitro. (A) Microneutralization assay. Different strains of viruses (100 TCID 50 H1N1, 120 TCID $_{50}$ H3N2, and $\left.200 \mathrm{TCID}_{50} \mathrm{H} 5 \mathrm{~N} 1\right)$ were incubated with $10 \mathrm{mg} / \mathrm{mL}$ of F.G.A or F.G.B for $1 \mathrm{~h}$ at $37^{\circ} \mathrm{C}$ and added to MDCK cells $\left(1 \times 10^{5}\right)$ for $18 \mathrm{~h}$ cultures. ELISA was done using primary antibody (Anti-NP) and secondary antibody (IgG-HRP) to determine percentage of growth based on control virus infection without ginseng samples. TCID 50 : Tissue culture infectious dose. (B) Plaque assay in MDCK cells. The H1N1 and F.G.A or F.G.B mixture incubated with MDCK cells monolayer for $30 \mathrm{~min}$, then covered with $1.5 \%$ agarose to culture for 3-5 days to determine percentage of control plaques. (C) Effects of fermented ginseng samples treatment prior to infection on viral growth in plaques. The mixture of H1N1 California/A/2009 and $10 \mathrm{mg} / \mathrm{mL}$ of F.G.A or F.G.B was incubated for 0, 5, 10, and $20 \mathrm{~min}$ at $37^{\circ} \mathrm{C}$. (D) Effects of fermented ginseng samples treatment postinfection on viral growth in plaques. MDCK monolayers were first infected with $\mathrm{H} 1 \mathrm{~N} 1 \mathrm{or} \mathrm{H} 5 \mathrm{~N} 1$ virus and incubated for $1 \mathrm{~h}$ at $37^{\circ} \mathrm{C}$. After washing away the virus, $10 \mathrm{mg} / \mathrm{mL}$ of F.G.A or F.G.B were added to virus-infected MDCK monolayers for $3 \mathrm{~h}$ or $6 \mathrm{~h}$. (E,F) ELISA for F.G.A-treated viral plates. The 96-wells were coated with H1N1 or H5N1 inactivated virus overnight, then incubated with $10 \mathrm{mg}$ of F.G.A or nonfermented ginseng for $1 \mathrm{~h}$ at $37^{\circ} \mathrm{C}$. The primary Anti-H1 HA and Anti-H5 HA and secondary goat anti-mouse IgG were used for ELISA test. (G) $8000 \mathrm{TCID}_{50}$ of rgH5N1 virus was incubated with different concentration of F.G.A or F.G.B for $30 \mathrm{~min}$, and neuraminidase activity was determined. (H) Cell viability test. $2 \mathrm{~mL}$ of EMEM medium (with $5 \mathrm{mg}$ and $10 \mathrm{mg} / \mathrm{mL}$ of F.G.A) was incubated with MDCK monolayer for $6 \mathrm{~h}$. Medium-ginseng mixture was removed, and cell viability was counted by trypan blue method. $*, * *, * * *$ symbols indicate statistical significance, $p<0.05, p<0.01$ and $p<0.001$ between the comparing groups. 'ns' indicates no significance.

\section{Discussion}

This study presents data demonstrating that fermented ginseng extract with more saponin component ginsenosides (F1, F2, PPT, Rh2, PPD) increased survival rates and protected the mice against body weight loss when coinoculated with influenza virus and ginseng samples. Fermented 
ginseng sample A (F.G.A) and sample B (F.G.B) presented different anti-influenza effects, possibly due to the different saponin components. Compared to F.G.B, F.G.A showed more potent antiviral activity against rgH5N1, H3N2, H1N1, and rgH7N9 influenza virus, not only in wild-type C57BL/6 and BALB/c mice but also in CD4 T cell-deficient mice, CD8 T cell-deficient mice, B cell-deficient mice and MHC-II-deficient mice with defects in CD4 and MHC II-antigen presentation. In F.G.A-treated group ( $250 \mu \mathrm{g}$ or higher dose), there were no virus replication and inflammation in the lung, while the mice with F.G.B still had substantial levels of viral loads and inflammation due to the influenza virus infection. It is assumed that the dose $(250,500 \mu \mathrm{g})$ of F.G.A conferred in vivo protection, inhibiting viral replication to a low level and preventing disease (no weight loss). It also limited the IgG production but allowed low viral replication, priming cellular immunity such as cross-protective T cell responses. During the secondary infection with the homologous virus (Figure 1) or H3N2 virus (Figure 3), the $250 \mu \mathrm{g}$ and $500 \mu \mathrm{g}$ F.G.A groups showed approximately $15-20 \%$ body weight loss and then recovered. This is a similar weight loss pattern as in the mock control infection, although the $250 \mu \mathrm{g}$ and $500 \mu \mathrm{g}$ F.G.A groups recovered better. It is assumed that F.G.A-treated groups mediated a low degree of secondary protection by a low level of (non-neutralizing) cellular immunity that had been induced during the primary infection despite the absence of detectable levels of virus-specific IgG antibodies. The F.G.A low dose concentration below $20 \mu \mathrm{g}$ allowed the replication of viruses to sufficient high levels, causing significant weight loss (disease), and stimulated the induction of high levels of virus-specific antibodies. Mice infected with a mixture of rgH5N1 virus and F.G.B displayed lower levels of inflammatory cytokines (IL-6, TNF- $\alpha$ ) in lung and in BALF compared to virus infection of the control mice. Meanwhile, F.G.A almost completely prevented the induction of proinflammatory cytokines, similar to those in uninfected mice. A similar pattern of protection against intranasal infection with mixtures of F.G.A and the virus was observed in both wild-type and CD4 knockout mice (Figure 5 and Supplementary Figure S1). Consistent with the approaches and results in our studies, extracts of other plants, such as Echinacea purpurea, have also been shown to have anti-influenza effects at a similarly low dose $(50 \mu \mathrm{g})$; direct contact between Echinacea purpurea and virus was found to be required for maximum antiviral effect [29]. In another relevant study [30], influenza virus $\left(1 \times 10^{3} \mathrm{EID}_{50}\right)$ was preincubated with equal volumes of ginseng extract, $\mathrm{Rb} 1$, or other ginsenosides $(2 \mathrm{mg} / \mathrm{mL})$ at $37^{\circ} \mathrm{C}$ for $1 \mathrm{~h}$. The virus and compound mixture were administered to naïve animals intranasally under anesthesia, reporting the antiviral activity of $\mathrm{Rb} 1$ ginsenoside. $\mathrm{Rb} 1$ was shown to interact with viral hemagglutinin protein, preventing viral attachment to the $2-3$ sialic acid receptors on the target cells [30].

Fermented ginseng samples appeared to exhibit more effective antiviral protection effects on influenza virus in vivo than in vitro. The data in this study suggest that direct contact between F.G.A and the virus resulted in antiviral effects in vivo, regardless of host adaptive immunity, such as CD4 and CD8 T cells. We did not observe protective effects of fermented ginseng extract when it was used to treat mice that had already received infection. Treatment of fermented ginseng extract before influenza infection via oral route [30] did not result in any substantial protection against influenza either. In in vitro experiments, F.G.A showed effects on inhibiting virus plaque formation and suppressing HA and NA activities, which likely partially contributed to the in vivo protection observed. A $100 \mu \mathrm{g}$ dose of F.G.A could effectively inhibit influenza virus replication in mice. It is possible that incubation of ginseng samples of ginsenosides compounds with influenza virus might induce conformational changes in viral surface proteins and reduce their infectivity to mammalian cells [30]. After infection of influenza virus, macrophages and neutrophils were rapidly recruited in the lung [31]. A high dose range (250-500 $\mu \mathrm{g}$ ) of fermented sample A might have neutralized most of the influenza viruses inoculated in a mixed form, and innate immune cells might have cleaned the remaining viruses. This protection through a mixture of F.G.A and virus in naïve mice was independent of adaptive immune components, such as CD4 T cells, CD8 T cells, MHCII, and B cells. There was no antibody response detected in the mice that received a high dose of fermented ginseng sample A mixed with influenza virus. The high dose F.G.A-protected mice without weight loss did not develop sufficient immunity 
and were not protected after secondary influenza virus infection. It is speculated that the dose $(250 \mu \mathrm{g})$ of F.G.A in CD4 KO mice conferred in vivo protection, inhibiting primary viral replication (rgH5N1 virus) to a low level and preventing disease. It also limited the IgG production but allowed low viral replication, priming cellular immunity such as cross-protective CD8 $\mathrm{T}$ cell responses. During the secondary infection with H3N2 virus, this $250 \mu \mathrm{g}$ F.G.A group (no detectable IgG antibodies against rgH5N1) showed approximately $15 \%$ body weight loss and then recovered, which was worse than the F.G.B $500 \mu \mathrm{g}$ dose (IgG antibodies against rgH5N1) that caused 5-6\% weight loss. The $250 \mu \mathrm{g}$ F.G.A group was only slightly better than the one observed in naïve infection. The $250 \mu \mathrm{g}$ F.G.B treatment group or mock treatment with infection, which experienced significant weight loss during the first infection and developed $\mathrm{rgH} 5$ virus-specific IgG antibodies, were fully protected against $\mathrm{H} 3$ virus in mice. There are multiple parameters in this observation of cross-protection in primary survival mice during the secondary infection. There might be cross-protective neutralizing IgG antibodies in mice that survived the primary infection. Cross-protection during the secondary infection is a well-known phenomenon in mice that survive infection with pathogenic influenza viruses. In previous studies, the mice that survived pathogenic influenza virus infection and experienced substantial weight loss during primary infection were shown to have heterosubtypic immunity through the induction of cross-reactive T cell and B cell responses [32-36]. The heterosubtypic protection was observed in the mice that survived primary infection even in a condition with $\mathrm{T}$ cell depletion during the secondary infection with an antigenically different virus [37]. Ginseng was shown to have anti-inflammatory activity, conferring the host with resistance to inflammatory disease against viral infections [38,39], which suggests a possibility of modulating inflammatory innate immune responses by F.G.B.

Moreover, antiviral activity of fermented ginseng was observed in a dose-dependent manner in vivo. High concentration of F.G.A (above $100 \mu \mathrm{g}$ ) related with full protection-no antibody response (Figure 2, F.G.A $500 \mu \mathrm{g}$ and $100 \mu \mathrm{g}$ ); low concentration of F.G.A (below $20 \mu \mathrm{g}$ ) related with no protection-antibody response (Figure 2, F.G.A $20 \mu \mathrm{g}$ ). It might have allowed low levels of virus replication in a threshold dose F.G.A $(50 \mu \mathrm{g})$ and produced the antibody response (Figure 2, F.G.A $50 \mu \mathrm{g})$. It has also been reported that ginsenosides interact with viral hemagglutinin proteins and prevent viral attachment with sialic acid receptors [30]. It might be possible that the active ginsenosides in fermented ginseng bind to hemagglutinin and thus prevent the infections. The data from the interference of binding primary anti-HA antibody suggest that F.G.A components might directly interact with virus HA proteins. In addition, F.G.A also inhibited HA activity when incubated in vitro with influenza virus (Supplementary Figure S3). Normally, neuraminidase plays an important role in budding and spreading of influenza virus. Neuraminidase also facilitates the entry of influenza virus into the human airway epithelium cells [40]. These in vitro test results indicate that inhibitory effects on HA and NA activity might have partially contributed to in vivo antiviral protection by fermented ginseng samples.

It is of interest to investigate which ginseng saponin ginsenosides function as the real effective antiviral component. After fermentation, the fermented ginseng sample A and B were both found to contain higher levels of compound $\mathrm{K}$ and active ginseng saponin components ginsenosides (PPT, $\mathrm{Rh} 2, \mathrm{PPD}, \mathrm{F} 1, \mathrm{~F} 2)$. It is speculated that combined effects of multiple substances in fermented ginseng samples might have such antiviral effects against influenza viruses with diverse subtypes. High concentrations $(>10 \mathrm{mg} / \mathrm{mL}$ ) of the fermented ginseng extract samples in in vitro antiviral test assays would not be in a range of an efficacious therapeutic level. Administration of mixed ginseng samples and viruses would not have much clinical relevance. In other aspects, this study focused on in vivo protective effects on influenza virus by fermented ginseng samples after direct contact with the virus. Inoculation with mixed pathogenic virus and fermented ginseng samples at appropriate dose resulted in protection in naïve mice without displaying weight loss during primary infection. In addition, the mice that survived or were protected during primary infection could develop immunity against homologous and different strains during the secondary infection. This finding could be applied to 
develop a safer live vaccine formulation for high-risk populations. Further studies on the safety, immunogenicity, and efficacy aspects should be performed.

Translating into clinical relevance, intranasal (spray) treatment with fermented ginseng samples at the site of virus entry during severe epidemic or pandemic seasons might have some protective benefits. Further studies remain to be done to uncover the anti-influenza virus mechanisms of fermented ginseng samples.

\section{Conclusions}

In the present study, we found that fermented ginseng extracts containing ginsenosides (PPT, PPD, Rh2, and Compound K) displayed more powerful antiviral effects against influenza viruses than nonfermented ginseng extracts. The antiviral protective effects were observed regardless of influenza virus strains, including various subtypes of H1N1, H3N2, H5N1, and H7N9. Mice that were inoculated with a moderate dose of fermented ginseng extract samples and a lethal dose of virus were protected against weight loss with $100 \%$ survival rates during primary infection as well as developed immunity against secondary viral infection.

Supplementary Materials: The following are available online at http:/ / www.mdpi.com/1999-4915/10/9/471/s1, Figure S1: In vivo primary and secondary protection against $\mathrm{rgH} 5 \mathrm{~N} 1$ and $\mathrm{H} 3 \mathrm{~N} 2$ virus in $\mathrm{CD} 4$ deficient mice, Figure S2: CD4 KO mice after infection with rgH5N1 influenza virus mixed with fermented ginseng sample A Lung viral replication are protected by clearing lung viral titers, Figure S3: Inhibition of hemagglutination activity in vitro by fermented ginseng extracts.

Author Contributions: S.-M.K., Y.W. and Y.-J.J. conceived and designed the experiments; Y.W., Y.-J.J., K.-H.K, Y.-J.K., Z.Z., and Y.K. performed the experiments; Y.W. and Y.-J.J. analyzed the data; H.-S.K., B.-Z.W., F.-S.Q., and S.-M.K. contributed reagents/materials/analysis tools; S.-M.K., Y.W. and Y.-J.J. wrote the paper.

Acknowledgments: This work was supported by NIH/NIAID grants AI105170 (S.M.K.), AI119366 (S.M.K.), and AI093772 (S.M.K.). The following reagent was obtained through the NIH Biodefense and Emerging Infections (BEI) Research Resources Repository: Anti-H1 HA (NR-19866 BEI resource) and Anti-H5 HA (NR-13449 BEI resource).

Conflicts of Interest: Heun-Soo Kang is an employee at Metabolab. However, the founding sponsors had no role in the design of the study; in the collection, analyses, or interpretation of data; in the writing of the manuscript; and in the decision to publish the results.

\section{References}

1. CDC. Disease Burden of Influenza. Available online: www.cdc.gov/flu/about/disease/burden.htm (accessed on 1 August 2018).

2. Centers for Disease Control and Prevention. Estimates of deaths associated with seasonal influenza-United States, 1976-2007. Morb. Mortal. Wkly. Rep. 2010, 59, 1057-1062.

3. Xu, J.; Davis, C.T.; Christman, M.C.; Rivailler, P.; Zhong, H.; Donis, R.O.; Lu, G. Evolutionary history and phylodynamics of influenza A and B neuraminidase (NA) genes inferred from large-scale sequence analyses. PLoS ONE 2012, 7, e38665. [CrossRef] [PubMed]

4. Nicholls, J.M.; Chan, R.W.; Russell, R.J.; Air, G.M.; Peiris, J.S. Evolving complexities of influenza virus and its receptors. Trends Microbiol. 2008, 16, 149-157. [CrossRef] [PubMed]

5. Tong, S.; Zhu, X.; Li, Y.; Shi, M.; Zhang, J.; Bourgeois, M.; Yang, H.; Chen, X.; Recuenco, S.; Gomez, J.; et al. New world bats harbor diverse influenza a viruses. PLoS Pathog. 2013, 9, e1003657. [CrossRef] [PubMed]

6. Maines, T.R.; Lu, X.H.; Erb, S.M.; Edwards, L.; Guarner, J.; Greer, P.W.; Nguyen, D.C.; Szretter, K.J.; Chen, L.M.; Thawatsupha, P.; et al. Avian influenza (H5N1) viruses isolated from humans in Asia in 2004 exhibit increased virulence in mammals. J. Virol. 2005, 79, 11788-11800. [CrossRef] [PubMed]

7. Shen, X.; Pitol, A.K.; Bachmann, V.; Hacker, D.L.; Baldi, L.; Wurm, F.M. A simple plasmid-based transient gene expression method using High Five cells. J. Biotechnol. 2015, 216, 67-75. [CrossRef] [PubMed]

8. Fan, M.; Huang, B.; Wang, A.; Deng, L.; Wu, D.; Lu, X.; Zhao, Q.; Xu, S.; Havers, F.; Wang, Y.; et al. Human influenza a (H7N9) virus infection associated with poultry farm, Northeastern China. Emerg. Infect. Dis. 2014, 20, 1902-1905. [CrossRef] [PubMed] 
9. Drake, J.W. Rates of spontaneous mutation among RNA viruses. Proc. Natl. Acad. Sci. USA 1993, 90, 4171-4175. [CrossRef] [PubMed]

10. Gultyaev, A.P.; Tsyganov-Bodounov, A.; Spronken, M.I.; van der Kooij, S.; Fouchier, R.A.; Olsthoorn, R.C. RNA structural constraints in the evolution of the influenza A virus genome NP segment. RNA Biol. 2014, 11, 942-952. [CrossRef] [PubMed]

11. Lee, J.S.; Hwang, H.S.; Ko, E.J.; Lee, Y.N.; Kwon, Y.M.; Kim, M.C.; Kang, S.M. Immunomodulatory activity of red ginseng against influenza A virus infection. Nutrients 2014, 6, 517-529. [CrossRef] [PubMed]

12. Yoo, D.G.; Kim, M.C.; Park, M.K.; Park, K.M.; Quan, F.S.; Song, J.M.; Wee, J.J.; Wang, B.Z.; Cho, Y.K.; Compans, R.W.; et al. Protective effect of ginseng polysaccharides on influenza viral infection. PLoS ONE 2012, 7, e33678. [CrossRef] [PubMed]

13. Dai, M.M.; Wu, H.; Li, H.; Chen, J.; Chen, J.Y.; Hu, S.L.; Shen, C. Effects and mechanisms of Geniposide on rats with adjuvant arthritis. Int. Immunopharmacol. 2014, 20, 46-53. [CrossRef] [PubMed]

14. Eom, S.J.; Hwang, J.E.; Jung, J.; Jee, H.S.; Kim, K.T.; Paik, H.D. Short communication: Antioxidative and antibacterial activities on Staphylococcus aureus and Escherichia coli O157:H4 in milk with added ginseng marc extract fermented by Lactobacillus plantarum KCCM 11613P. J. Dairy Sci. 2017, 100, 7788-7792. [CrossRef] [PubMed]

15. Jang, S.H.; Park, J.; Kim, S.H.; Choi, K.M.; Ko, E.S.; Cha, J.D.; Lee, Y.R.; Jang, H.; Jang, Y.S. Oral administration of red ginseng powder fermented with probiotic alleviates the severity of dextran-sulfate sodium-induced colitis in a mouse model. Chin. J. Nat. Med. 2017, 15, 192-201. [CrossRef]

16. Jang, S.H.; Park, J.; Kim, S.H.; Choi, K.M.; Ko, E.S.; Cha, J.D.; Lee, Y.R.; Jang, H.; Jang, Y.S. Red ginseng powder fermented with probiotics exerts antidiabetic effects in the streptozotocin-induced mouse diabetes model. Pharm. Boil. 2017, 55, 317-323. [CrossRef] [PubMed]

17. Song, J.M.; Van Rooijen, N.; Bozja, J.; Compans, R.W.; Kang, S.M. Vaccination inducing broad and improved cross protection against multiple subtypes of influenza A virus. Proc. Natl. Acad. Sci. USA 2011, 108, 757-761. [CrossRef] [PubMed]

18. Song, X.; Chen, J.; Sakwiwatkul, K.; Li, R.; Hu, S. Enhancement of immune responses to influenza vaccine (H3N2) by ginsenoside Re. Int. Immunopharmacol. 2010, 10, 351-356. [CrossRef] [PubMed]

19. Quan, F.S.; Compans, R.W.; Nguyen, H.H.; Kang, S.M. Induction of heterosubtypic immunity to influenza virus by intranasal immunization. J. Virol. 2008, 82, 1350-1359. [CrossRef] [PubMed]

20. Jung, Y.J.; Lee, Y.T.; Ngo, V.L.; Cho, Y.H.; Ko, E.J.; Hong, S.M.; Kim, K.H.; Jang, J.H.; Oh, J.S.; Park, M.K.; et al. Heat-killed Lactobacillus casei confers broad protection against influenza A virus primary infection and develops heterosubtypic immunity against future secondary infection. Sci. Rep. 2017, 7, 17360. [CrossRef] [PubMed]

21. Lee, Y.N.; Kim, M.C.; Lee, Y.T.; Hwang, H.S.; Lee, J.; Kim, C.; Kang, S.M. Cross Protection against Influenza A Virus by Yeast-Expressed Heterologous Tandem Repeat M2 Extracellular Proteins. PLoS ONE 2015, 10, e0137822. [CrossRef] [PubMed]

22. Sha, Z.; Kang, S.M.; Compans, R.W. Mucosal immunization of CD4(+) T cell-deficient mice with an inactivated virus induces IgG and IgA responses in serum and mucosal secretions. Virology 2005, 331, 387-395. [CrossRef] [PubMed]

23. Simonsen, L.; Clarke, M.J.; Schonberger, L.B.; Arden, N.H.; Cox, N.J.; Fukuda, K. Pandemic versus epidemic influenza mortality: A pattern of changing age distribution. J. Infect. Dis. 1998, 178, 53-60. [CrossRef] [PubMed]

24. Doyle, T.M.; Hashem, A.M.; Li, C.; Van Domselaar, G.; Larocque, L.; Wang, J.; Smith, D.; Cyr, T.; Farnsworth, A.; He, R.; et al. Universal anti-neuraminidase antibody inhibiting all influenza A subtypes. Antivir. Res. 2013, 100, 567-574. [CrossRef] [PubMed]

25. Doyle, T.M.; Jaentschke, B.; Van Domselaar, G.; Hashem, A.M.; Farnsworth, A.; Forbes, N.E.; Li, C.; Wang, J.; He, R.; Brown, E.G.; et al. The universal epitope of influenza A viral neuraminidase fundamentally contributes to enzyme activity and viral replication. J. Biol. Chem. 2013, 288, 18283-18289. [CrossRef] [PubMed]

26. Doyle, T.M.; Li, C.; Bucher, D.J.; Hashem, A.M.; Van Domselaar, G.; Wang, J.; Farnsworth, A.; She, Y.M.; Cyr, T.; He, R.; et al. A monoclonal antibody targeting a highly conserved epitope in influenza B neuraminidase provides protection against drug resistant strains. Biochem. Biophys. Res. Commun. 2013, 441, 226-229. [CrossRef] [PubMed] 
27. Wohlbold, T.J.; Nachbagauer, R.; Xu, H.; Tan, G.S.; Hirsh, A.; Brokstad, K.A.; Cox, R.J.; Palese, P.; Krammer, F. Vaccination with adjuvanted recombinant neuraminidase induces broad heterologous, but not heterosubtypic, cross-protection against influenza virus infection in mice. MBio 2015, 6, e02556. [CrossRef] [PubMed]

28. Thomas, P.G.; Keating, R.; Hulse-Post, D.J.; Doherty, P.C. Cell-mediated protection in influenza infection. Emerg. Infect. Dis. 2006, 12, 48-54. [CrossRef] [PubMed]

29. Pleschka, S.; Stein, M.; Schoop, R.; Hudson, J.B. Anti-viral properties and mode of action of standardized Echinacea purpurea extract against highly pathogenic avian influenza virus (H5N1, H7N7) and swine-origin H1N1 (S-OIV). Virol. J. 2009, 6, 197. [CrossRef] [PubMed]

30. Dong, W.; Farooqui, A.; Leon, A.J.; Kelvin, D.J. Inhibition of influenza A virus infection by ginsenosides. PLoS ONE 2017, 12, e0171936. [CrossRef] [PubMed]

31. Hashimoto, Y.; Moki, T.; Takizawa, T.; Shiratsuchi, A.; Nakanishi, Y. Evidence for phagocytosis of influenza virus-infected, apoptotic cells by neutrophils and macrophages in mice. J. Immunol. 2007, 178, 2448-2457. [CrossRef] [PubMed]

32. Guo, H.; Santiago, F.; Lambert, K.; Takimoto, T.; Topham, D.J. T cell-mediated protection against lethal 2009 pandemic H1N1 influenza virus infection in a mouse model. J. Virol. 2011, 85, 448-455. [CrossRef] [PubMed]

33. Nguyen, H.H.; Moldoveanu, Z.; Novak, M.J.; van Ginkel, F.W.; Ban, E.; Kiyono, H.; McGhee, J.R.; Mestecky, J. Heterosubtypic immunity to lethal influenza A virus infection is associated with virus-specific CD8(+) cytotoxic T lymphocyte responses induced in mucosa-associated tissues. Virology 1999, 254, 50-60. [CrossRef] [PubMed]

34. O’Neill, E.; Krauss, S.L.; Riberdy, J.M.; Webster, R.G.; Woodland, D.L. Heterologous protection against lethal A/HongKong/156/97 (H5N1) influenza virus infection in C57BL/6 mice. J. Gen. Virol. 2000, 81, 2689-2696. [CrossRef] [PubMed]

35. Nguyen, H.H.; van Ginkel, F.W.; Vu, H.L.; McGhee, J.R.; Mestecky, J. Heterosubtypic immunity to influenza A virus infection requires B cells but not CD8+ cytotoxic T lymphocytes. J. Infect. Dis. 2001, 183, 368-376. [CrossRef] [PubMed]

36. Nguyen, H.H.; Zemlin, M.; Ivanov, I.I.; Andrasi, J.; Zemlin, C.; Vu, H.L.; Schelonka, R.; Schroeder, H.W., Jr.; Mestecky, J. Heterosubtypic immunity to influenza A virus infection requires a properly diversified antibody repertoire. J. Virol. 2007, 81, 9331-9338. [CrossRef] [PubMed]

37. Kim, M.C.; Lee, Y.N.; Kim, Y.J.; Choi, H.J.; Kim, K.H.; Lee, Y.J.; Kang, S.M. Immunogenicity and efficacy of replication-competent recombinant influenza virus carrying multimeric M2 extracellular domains in a chimeric hemagglutinin conjugate. Antivir. Res. 2017, 148, 43-52. [CrossRef] [PubMed]

38. Lee, J.S.; Cho, M.K.; Hwang, H.S.; Ko, E.J.; Lee, Y.N.; Kwon, Y.M.; Kim, M.C.; Kim, K.H.; Lee, Y.T.; Jung, Y.J.; et al. Ginseng diminishes lung disease in mice immunized with formalin-inactivated respiratory syncytial virus after challenge by modulating host immune responses. J. Interferon Cytokine Res. 2014, 34, 902-914. [CrossRef] [PubMed]

39. Lee, J.S.; Lee, Y.N.; Lee, Y.T.; Hwang, H.S.; Kim, K.H.; Ko, E.J.; Kim, M.C.; Kang, S.M. Ginseng protects against respiratory syncytial virus by modulating multiple immune cells and inhibiting viral replication. Nutrients 2015, 7, 1021-1036. [CrossRef] [PubMed]

40. Matrosovich, M.N.; Matrosovich, T.Y.; Gray, T.; Roberts, N.A.; Klenk, H.D. Neuraminidase is important for the initiation of influenza virus infection in human airway epithelium. J. Virol. 2004, 78, 12665-12667. [CrossRef] [PubMed]

(C) 2018 by the authors. Licensee MDPI, Basel, Switzerland. This article is an open access article distributed under the terms and conditions of the Creative Commons Attribution (CC BY) license (http:/ / creativecommons.org/licenses/by/4.0/). 